CUPAUAM 25.2, 1999, pp. 291-313

\title{
ARQUEOLOGÍA DE UNA CASA DEL RENACIMIENTO EN TOLEDO $^{[1]}$
}

\author{
ARTURO RuIz TABOADA \\ Departamento de Prehistoria y Arqueología \\ Universidad Autónoma de Madrid
}

\section{Resumen}

El artículo muestra los resultados de una intervención arqueológica en un edificio del siglo XVI en Toledo. Dicha intervención ha permitido conocer alguna de las características de la arquitectura civil popular del período renacentista. El trabajo se ha centrado en el diseño estructural, el tipo de obra y los elementos ornamentales empleados. Además, el análisis contrasta los datos históricos sobre la evolución urbanística de la ciudad con las diferentes fases constructivas del mismo. Aunque la casa es de nueva planta, resulta interesante documentar el uso de estructuras o trazados constructivos más antiguos como complemento a la nueva edificación, práctica habitual en la ciudad de Toledo.

\begin{abstract}
Although much has been written about renaissance architecture in the city of Toledo (Spain), there has been little published about private houses and the so-called domestic architecture. The main goal of the paper is to highlight for the scholars on renaissance architecture the possibilities of standing-building research for dating purposes and understanding historical processes. A detailed archaeological analysis of the structural design of the house allows us to recognize certain regularities in foundation and different materials used in the building.
\end{abstract}

[1] La información procede de una intervención arqueológica en el número 6 de la calle Hospedería de San Bernardo (Toledo) entre marzo de 2000 y junio de 2001. El proyecto de rehabilitación está diseñado por AMA, Estudio de Arquitectura. La casa es propiedad de Emilio Navarro. 
El estudio de la arquitectura civil renacentista en Toledo, especialmente la relacionada con construcciones dedicadas a vivienda, se ve dificultado por la falta de datos representativos sobre edificación y contexto urbano. Tradicionalmente, la investigación se ha referido a edificios públicos y privados, en general propiedad de la Iglesia y la nobleza. Estos edificios se han conservado por la calidad de su construcción y el uso continuado. En cambio, las edificaciones que no eran propiedad de estos dos estamentos se han conservado peor a causa de las constantes remodelaciones a las que han estado sometidas a partir del siglo XVII. No obstante, se conservan muchos edificios de este tipo, pero su reconocimiento arqueológico y documental se ve obstaculizado por el uso que se ha dado a estas viviendas: pasaron de pertenecer a una sola familia en el siglo XVI y principios del XVII, a unidades vecinales compuestas por varias familias.

Esta circunstancia contrasta con la abundante documentación sobre arquitectura civil y religiosa recogida en gran número de publicaciones. Sin duda la más representativa son los cuatro volúmenes que Fernando Marías publica sobre el renacimiento en Toledo entre 1541 y 1631 (MARIAS, 1983; 1985; 1986a y 1986b). Este autor habla del entorno social de la arquitectura, de su evolución en el contexto urbanístico de la ciudad y de las personas involucradas en su construcción, propietarios, arquitectos y maestros de obras. Además, Marías reconoce las enormes limitaciones que ofrece el estudio de la arquitectura doméstica en la ciudad, considera que estudios de este tipo tienen escasas probabilidades de éxito por carecer de fuentes documentales que hablen de construcciones populares y de edificaciones que hayan trascendido a nuestros días sin sufrir el inevitable azote de la trasformación urbanística a lo largo de los siglos (MARÍAS, 1986b: 83). A raíz de la publicación de este tratado surgen nuevos trabajos que recogen la evolución arquitectónica de la ciudad y reflejan aspectos concretos de la arquitectura renacentista toledana. Existen libros de consulta con una amplia documentación gráfica, entre ellos destacan Arquitectura y mecenazgo: La imagen de Toledo en el Renacimiento (DÍEZ DEL CORRAL, 1987) y Arquitecturas de Toledo, editado por la Junta de Comunidades de Castilla La Mancha (DÍEZ DEL CORRAL y otros, 1992). Como ocurre con este tipo de obras, la temática es sobre arquitectura civil y religiosa, sin que se haga mención de la arquitectura doméstica. Otras referencias indirectas a la arquitectura del renacimiento en Toledo las tenemos en dos publicaciones ya clásicas: la casa toledana (TÉLLEZ, 1948-1949) e bistoria de las calles de Toledo (PORRES MARTÍN-CLETO, 1971).

No menos representativos son los trabajos que se centran en aspectos particulares de la edificación como el tipo y material empleado en la obra o las diferencias tipológicas existentes entre estructuras murarias (CASTAÑOS Y MONTIJANO, 1918; MIRANDA SÁNCHEZ, 1995; ROJAS RODRÍGUEZ MALO y VILLA GONZÁLEZ, 1999; VVAA, 1999).

La entrada en vigor de la Ley de Patrimonio Histórico de Castilla La Mancha (4/1990) ha permitido aplicar una serie de normas para proteger el patrimonio arqueológico e histórico en ciudades como Toledo. El artículo 21 de la ley obliga a la propiedad o promotora de las obras a adjuntar a la solicitud de licencia un estudio arqueológico que recoja el valor histórico del inmueble y las líneas de actuación para su conservación. La aplicación de este tipo de leyes o la puesta en marcha de planes especiales como el Plan Especial del Conjunto Histórico de Toledo (BUSQUETS MORENO, 1996) ha favorecido la implantación 
de lo que, acertada o desacertadamente, se ha denominado gestión preventiva del patrimonio o arqueología urbana.

Durante la última década del siglo XX y a expensas de esta ley, la investigación sobre la evolución urbanística en la ciudad de Toledo experimenta un cambio cuantitativo al aumentar el número de informes arqueológicos sobre obras. Por el contrario, no se puede hablar de un cambio cualitativo en cuanto que estos informes rara vez llegan a publicarse. Por poner un ejemplo, en los últimos años sólo en tres publicaciones promovidas desde la administración se recogen actuaciones arqueológicas desarrolladas en Toledo: Actas del I Congreso de Arqueología de la Provincia de Toledo (CARROBLES SANTOS, 1990), Actas del II Congreso de Arqueología de la Provincia de Toledo (CARROBLES SANTOS y RUIZ TABOADA, 2001) y el libro Toledo; arqueología en la ciudad (1996), coordinado por el Servicio de Bienes de Interés Cultural de la Consejería de Educación y Cultura de la Junta de Comunidades de Castilla La Mancha.

Esta última monografía, pese a ser la mejor publicada sobre gestión de patrimonio en Toledo, no deja de ser un mero inventario de actuaciones arqueológicas en solares y obras. De todas ellas, sólo dos tratan aspectos de arquitectura doméstica renacentista: el Museo de Arte Contemporáneo (PAZ ESCRIBANO y DE JUAN GARCÍA, 1996), ejemplo de arquitectura palacial, y el número 6 de la Calle Alfonso X el Sabio (BARRIO ALDEA y MAQUEDANO CARRASCO, 1996), civil familiar. En ambos trabajos se prioriza el estudio del subsuelo y de las estructuras de cimentación, bóvedas y aljibes en detrimento de sus alzados. En este sentido, conviene tener presente que las transformaciones arquitectónicas del siglo XVI han quedado fosilizadas en la inmensa mayoría de casas que aún hoy forman parte del tejido urbano de la ciudad. Llama la atención que en ninguno de los trabajos contenidos en esa publicación se hace mención a dichas transformaciones.

\section{ANÁLISIS URBANÍSTICO E HISTÓRICO}

El desarrollo de la ciudad ha estado condicionado por diversos factores de orden económico, social, político y religioso desde su fundación hasta nuestros días. El asentamiento más antiguo se fecha en los últimos años del segundo milenio antes de Cristo. Dicho asentamiento ocupaba las cimas de los diferentes cerros que forman el peñón de la ciudad. Desde un punto de vista espacial, su límite externo ha estado siempre definido por el río y los distintos trazados de la muralla norte. Por el contrario, el espacio interno ha sufrido diversas transformaciones desde su municipalización en época romana hasta mediados del $\mathrm{XX}$, época en la que se produce el último auge constructivo.

Para comprender la casa localizada en el número 6 de Hospedería de San Bernardo es imprescindible conocer el contexto histórico de su construcción. El punto de partida es la Alta Edad Media y finaliza en pleno siglo XVI con el aumento demográfico en época de Carlos V. Durante la Edad Media, musulmanes y cristianos juegan un papel decisivo en el desarrollo de la ciudad. No obstante, son los judíos, etnia minoritaria, los que van a condicionar el desarrollo urbanístico hasta su expulsión por los Reyes Católicos en el siglo XV. Según se recoge en un reciente estudio (CARROBLES SANTOS, 2001), la zona donde se 
sitúa la casa ofrece una posición marginal con respecto a la división interna de la ciudad, al formar parte del límite norte del antiguo barrio judío (agradezco a Jesús Carrobles los comentarios hechos a este respecto).

Durante época islámica la población judía se concentra en el extremo más occidental del peñón. Desde un primer momento, tanto árabes, que mandan amurallar el sector ocupado por los judíos en el siglo IX, como cristianos a partir del siglo XI, se ven obligados a convivir con una minoría nunca bien asumida por la población (RUBIERA MATA, 1991:110). El límite norte de la antigua ciudad judía (Medinat al-Yahud) discurría desde el cerro de la Virgen de Gracia (la actual Consejería de Agricultura) a la plaza de San Antonio por la calle Hospedería de San Bernardo (Figura 1). Como señala Carrobles en su informe, esta disposición fronteriza favorece los enfrentamientos entre árabes y judíos primero y cristianos y judíos después. La situación obliga a los habitantes de esta parte de la ciudad a crear mecanismos de autodefensa, las casas se agrupan en adarves con cierres y puertas en plena calle. Hoy se conserva el trazado de alguno de estos adarves en calles sin salida de la zona como el callejón del Alarife (ROJAS RODRÍGUEZ MALO, 1996), callejón de las Siete Revueltas (CARROBLES SANTOS, 2001) o el situado en la Calle de Las Bulas (ROJAS RODRÍGUEZ MALO y VILLA GONZÁLEZ, 1999b). Estos dos últimos se localizan en las inmediaciones de la calle Hospedería de San Bernardo.

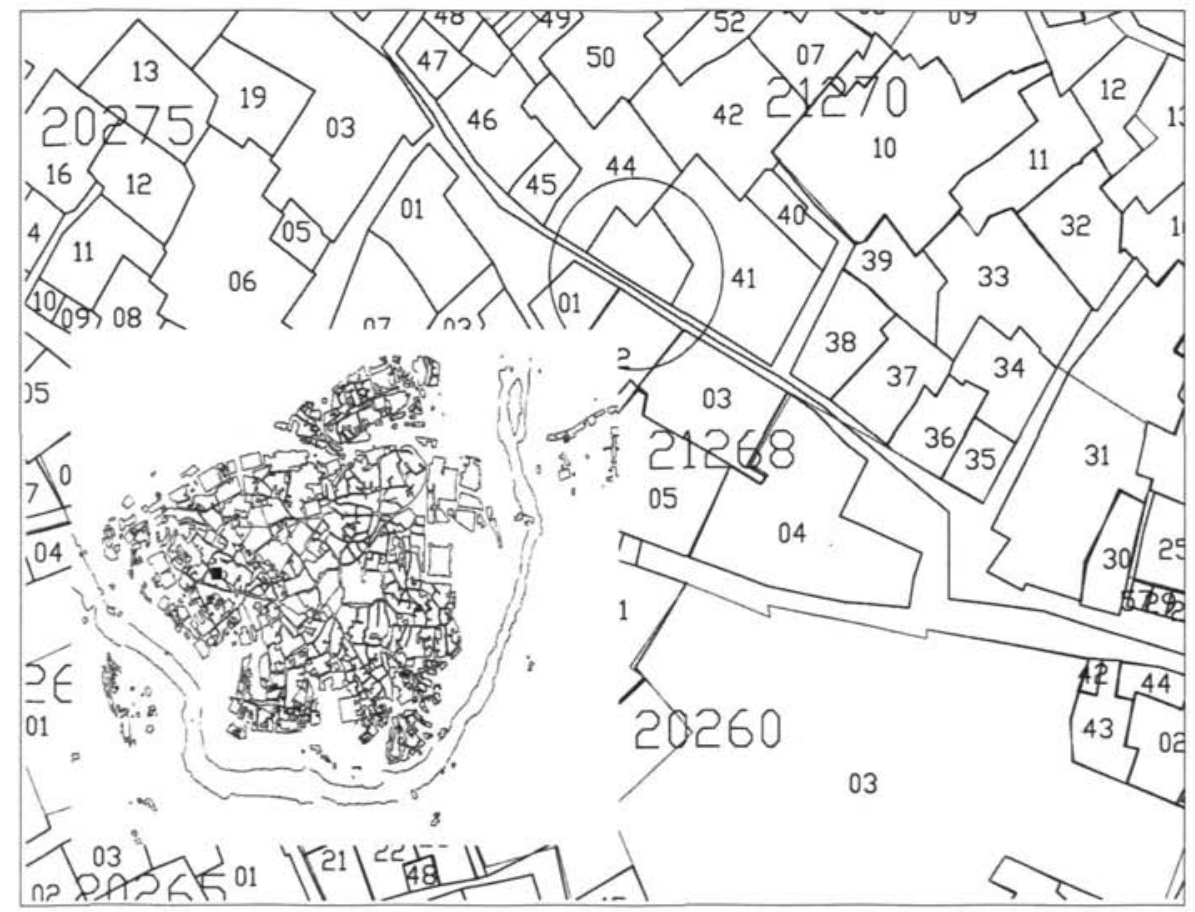

Figura 1. Plano de situación del inmueble 
La expulsión de los judíos en 1492 posibilita el fin de este efecto frontera. El cese de las hostilidades hace que la zona de contacto entre estos dos mundos, representada entre otras por la calle Hospedería de San Bernardo, pierda su condición de marginal y se convierta en una zona de expansión destinada a albergar la nobleza que acompaña la nueva corte durante el reinado de Carlos V. Los adarves desaparecen con el desarrollo de ese nuevo barrio residencial. Se remodelan o construyen nuevas casas sobre las antiguas o se edifica en zonas destinadas anteriormente para corrales o huertas. Como veremos más adelante, esta transformación urbanística ha quedado reflejada en la obra y diseño de la casa.

Toledo pasa a ser en el siglo XVI una de las ciudades españolas con mayor volumen de población (PORRES MARTÍN CLETO y otros, 1992: 19). El posterior traslado de la corte a Madrid durante el reinado de Felipe II provoca en la ciudad una serie de cambios que marcarán la evolución urbanística hasta bien entrado el siglo XIX. Como señala Fernando Marías (1983: 124), la pérdida de la capitalidad va acompañada de un descenso de la población y de la potenciación de la sede primada, Toledo como centro religioso. A lo largo del siglo XVII se produce una monasterización de la vida urbana con la creación y posterior desarrollo de lo que se ha venido a denominar la ciudad conventual. Este nuevo esquema urbanístico ha perdurado hasta nuestros días.

Lo singular de la edificación en el número 6 de la calle Hospedería de San Bernardo es que no se ve afectada por ninguna de estas últimas transformaciones. Desde su construcción, los únicos elementos materiales que constatan el paso del tiempo son los sucesivos revocos de las paredes, las tabicaciones, falsos techos, el cambio de nivel con respecto al suelo original y, por último, su propio deterioro estructural. El único elemento ornamental añadido es la baldosa hidráulica de la solera del patio y alguna de las habitaciones, decorada con motivos geométricos de aire modernista, fechada en los primeros años del siglo XX.

\section{DESCRIPCIÓN DEL INMUEBLE}

La casa tiene tres plantas, un sótano y dos fachadas. La fachada principal (sur) da a la Calle Hospedería de San Bernardo. La segunda fachada (este) da a una zona destinada a huerto, hoy perdida. La planta es irregular y se corresponde con el esquema constructivo clásico de la ciudad de Toledo. Aprovecha, por una parte, el recorrido natural de la curva de nivel de la orografía de la ciudad y, por otra, se adapta a la estructura arquitectónica diseñada en época bajomedieval de la que tan sólo se conservan las bóvedas del sótano.

El espacio se organiza alrededor de un patio en tres crujías irregulares en forma de "U" con una columna de granito como único elemento portante. El patio posee dos accesos, uno directo desde la calle y otro desde el corral a través de una de las habitaciones de la planta baja (Figura 2).

En la fachada este todavía se conservan dos vanos de ventana en los pisos primero y segundo y el acceso al corral mediante una puerta abocinada de características similares 
a la principal. Además de las evidencias arquitectónicas, en el Registro de la Propiedad Urbana del Ayuntamiento de Toledo de 1913 se menciona la existencia de una zona destinada a huerto, medianera con la casa, que hoy se ha perdido con la construcción de un nuevo edificio (agradezco a Emilio Navarro la documentación que recoge dicha información).

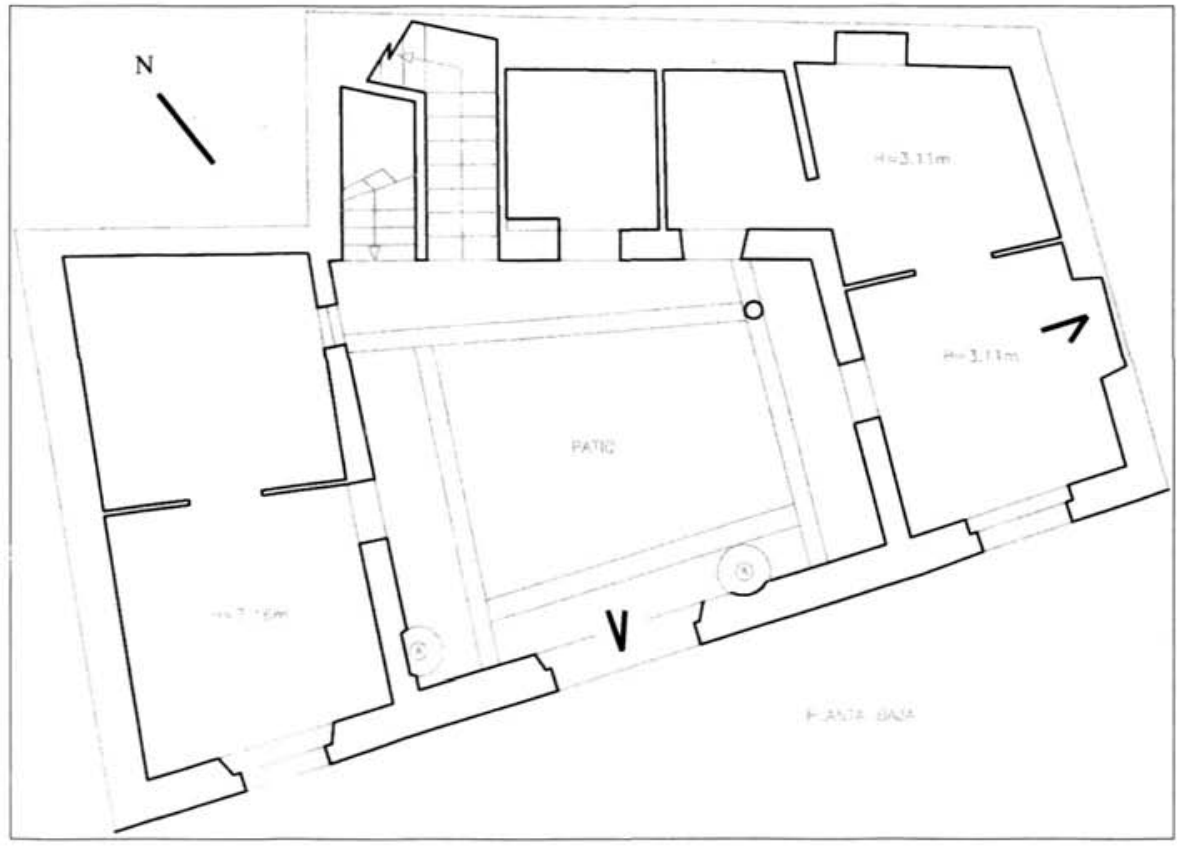

Figura 2. Planta baja, según AMA, Estudio de Arquitectura. En el plano se aprecia el acceso principal desde la calle y los brocales del pozo y aljibe localizados en el muro frontero sur, el acceso actualmente tapiado al corral en la crujía este y la escalera principal de subida a las dos plantas y bajada al sótano, todos estos elementos son contemporáneos. Los huecos de las ventanas del muro frontero se distribuyen simétricamente en relación a la puerta principal. El patio, de estructura irregular sobre el que se distribuyen las tres crujias, posee una única columna estructural y cuatro vigas maestras.

La casa mantiene la estructura original del bajo medieval así como el entramado de vigas de madera de los techos. Los alfarjes son lisos y sin decoración. Su estado de conservación es muy bueno, apreciándose tan sólo el repintado y deterioro de algún sector. El patio posee una galería delimitada por una balaustrada de madera corrida que se repite en los dos pisos superiores. Esta baranda estaba abierta y describe el mismo trazo irregular del patio. En la actualidad la galería se ha tapiado en su totalidad y tiene como única fuente de luz cuatro ventanas por planta.

El patio posee un aljibe y un pozo integrados mediante una hornacina en el interior del muro frontero, aljibe, y la esquina del muro de una de las habitaciones de la planta baja situada en la crujía oeste, pozo. Ambos poseen dos brocales de granito con decoración geo- 
métrica en resalte. Los brocales ahornacinados son típicos de los patios toledanos del renacimiento.

En cuanto al sótano, lo forman dos bóvedas orientadas al oeste y norte (Figura 3):

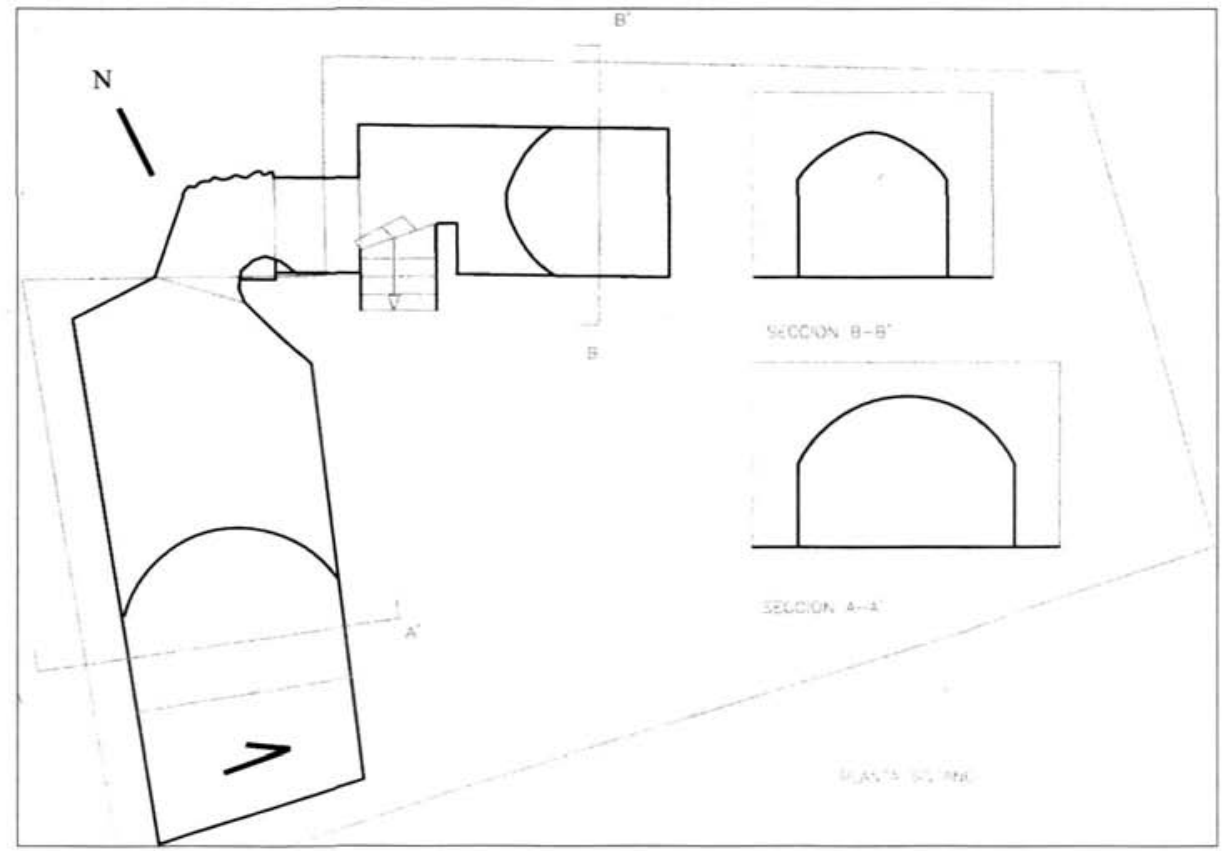

Figura 3. Planimetría de las dos bóvedas del sótano, según AMA Estudio de Arquitectura. El acceso marcado corresponde a la casa renacentista. El acceso original se ha localizado en el extremo sur de la bóveda, hoy cegado mediante un forjado de madera.

1. Bóveda oeste. Es la más amplia, de medio cañón. Posee dos ventanas abocinadas, una de ellas tapida a raíz de las sucesivas remodelaciones del patio y un arco ciego, también tapiado con un muro de ladrillo con zócalo de mampostería que comunica con la bajante del pozo del patio. La bóveda finaliza al sur con un pequeño forjado de vigas de madera. En el trascurso de las obras de acondicionamiento del muro medianero de la crujía oeste apareció el primitivo acceso a la bóveda, que coincide con el forjado, y que debió pertenecer a la edificación anterior. Dicho acceso fue abandonado al plantear las obras de la nueva casa trasladándose a la segunda bóveda, en la crujía norte. Este cambio de acceso al sótano permite establecer dos fases constructivas distintas: la primera de época bajomedieval, que se corresponde con la antigua edificación, bóvedas y alguno de los muros medianeros. La segunda Moderna, a la que corresponde el resto de la superficie construida.

Un dato de interés es la relación arco de acceso a la bajante del pozo, el cual aparece integrado en la bóveda, y el forjado del antiguo acceso. Dicha relación permite supo- 
ner que, al menos, la bajante del pozo es de época bajomedieval al poseer el mismo diseño y tipo de obra. El constructor de la nueva edificación reintegra las bajantes y sustituye los antiguos brocales por unos nuevos.

Por último, en el suelo de esta bóveda se aprecia como la roca madre de granito aflora ocupando una gran parte de su superficie e impidiendo que el suelo tenga un piso uniforme.

2. Bóveda norte. Conecta con la bóveda oeste a través de un pequeño corredor dibujando una estructura en forma de "L". Su tipología constructiva es distinta a la anterior y presenta un ligero apuntamiento, dicho apuntamiento puede ser debido a las características orográficas del terreno al aflorar la roca madre. La bóveda se encuentra alterada por la construcción de una escalera que comunica directamente con el patio. Esta escalera rompe claramente la estructura de ladrillos de la bóveda y hace necesario la construcción de un pequeño muro de descarga que refuerza la estructura. La construcción de este acceso está en relación con la edificación de la casa renacentista.

Asociaciones similares de bóveda de medio cañón - bóveda apuntada son bastante frecuentes en la ciudad de Toledo. Como ejemplo las existentes en el sótano del antiguo palacio conocido como casa de las cadenas en la calle de las Bulas 15.

La estructura portante del inmueble responde al tradicional aparejo toledano. La distribución de este paramento no es uniforme y varía en función de su localización en el inmueble. En líneas generales, la planta baja cuenta con el mayor espesor del muro ( 50 centímetros). Este muro alterna dos tipos de obra: ladrillo y mampostería trabada en cal con cajones de ladrillo y doble encintado. Esta última se generaliza en este momento y perdura hasta hoy. En el resto de los pisos, con muros de menor espesor (15 centímetros), la obra que predomina es el armazón de madera relleno de ladrillo y cascote trabado con cal sin una disposición uniforme en planta. Este tipo de obra se repite en Toledo hasta bien entrado el siglo XX. El aparejo va acompanado de un revestimiento en su superficie interior y exterior. Por desgracia, el alto grado de deterioro de la fachada ha hecho que una gran parte de ese revoco se haya perdido. En la zona de sombra se pueden intuir restos de pintura de lo que debió ser la decoración original, la simulación de cornisas debía ir acompanada de líneas perpendiculares y paralelas de color rojo imitando losas o ladrillos (Figura 4).

En habitaciones y pasillos se han documentado dos niveles de revestimiento diferentes. Uno perteneciente a la obra renacentista y otro contemporáneo. El más antiguo consiste en un revoco de cal, de color blanco, con un zócalo pintado en negro que recorre la mayor parte de las habitaciones. Sólo hay evidencia de estos revocos en las dos últimas plantas. El nivel de deterioro es muy alto, habiendo sido imposible su recuperación. 


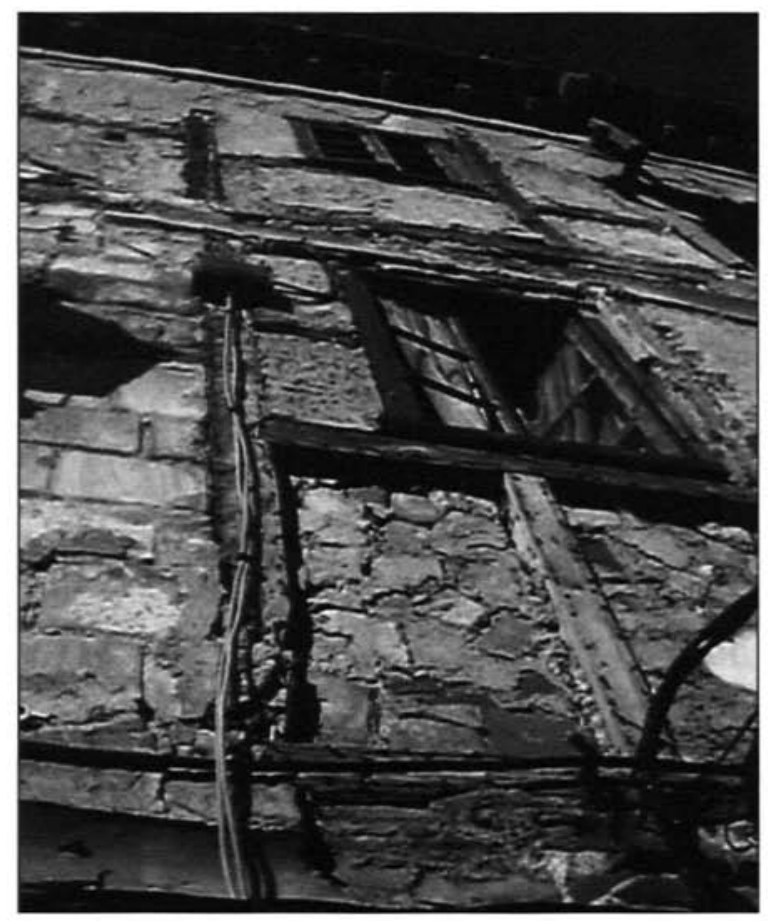

Figura 4. Detalle de la fachada principal

\section{ALBAÑILERÍA Y OBRA}

La fachada posee una distribución simétrica de vanos. La planta baja es la más representativa. En ella se abren dos huecos rectangulares para ventanas y uno para la puerta de acceso, las tres aperturas son abocinadas y utilizan una viga de madera a modo de dintel. La puerta principal no posee ningún elemento ornamental que la delimite y su obra es de ladrillo. En el momento de su construcción debió estar revocada en su totalidad, revoco que en la actualidad se ha perdido, además conserva el quicio original de granito. Las medidas de la puerta śon 2,80 de alto por 2,10 de ancho mientras que la de las ventanas a ambos lados es la misma: 1,35 de alto por 1,20 de ancho.

La obra de la fachada es bastante irregular dependiendo de sectores y plantas. La planta baja alterna obra de ladrillo y mampostería. La obra en el resto de las plantas se compone de un entramado de vigas de madera relleno de cascotes.

Se han documentado cinco tipos de obra en los muros de la casa:

1. Mampostería encintada entre cajones de ladrillo (cara interior del muro de la fachada sur, planta baja). 
2. Ladrillo (cara interior del muro de la fachada este, planta baja).

3. Entramado de vigas con relleno de cascote (Plantas uno y dos, cara interior del muro de la fachada este).

4. Ladrillo y tapial (Planta segunda, cara interior del muro medianero oeste).

5. Mampostería irregular (Planta segunda, cara interior del muro medianero norte).

\section{Mampostería encintada entre cajones de ladrillo (Figura 5).}

Es el muro de la fachada principal. El tipo de obra es muy común a partir del siglo XVI aunque el mismo patrón constructivo se puede documentar en edificios de principios del XXI. Se diferencia del resto de paramentos por su buena factura, integra además la hornacina del aljibe y da apoyo a una de las vigas maestras del patio. Lo más interesante es la solución que ofrece en el marco de la puerta de acceso. El muro de mampostería da paso a un paño uniforme de ladrillos que delimita el marco exterior de la puerta, no apreciándose que haya existido ningún elemento ornamental en piedra que lo delimitara.

\section{Ladrillo (Figura 6)}

Es el muro de la fachada que tiene acceso al corral. Posee unas características constructivas similares al anterior aunque en este caso la obra es enteramente de ladrillo. Llama la atención el cambio de espesor del muro de la planta baja con respecto al resto de las plantas. Dicho cambio se debe a causas estructurales, al no ser necesario repetir grosores pues las plantas no soportan excesivo peso.

\section{Entramado de vigas con relleno de cascote (Figuras 7 y 8 ).}

La obra es muy típica de la arquitectura toledana de este último milenio. La técnica constructiva es bastante simple, armazón de vigas de madera relleno con material de obra de distinta calidad en función de la zona donde se localice. En nuestro caso, el armazón de madera del primer piso está relleno de ladrillo de era trabado con cal, mientras que el segundo con cascote.

En este armazón de madera, cuyas piezas se encuentran trabadas y unidas unas con otras, se han habilitado sendos huecos en cada uno de los pisos para las ventanas que dan al huerto o jardín.

\section{Ladrillo y tapial (Figura 9)}

Es uno de los muros más antiguos de la casa. Llama la atención la forma en la que se ha reutilizado la obra original. Dicha obra se conserva en algunos tramos, en otros se ha procedido a habilitarlo para contener tapial, lo que, en definitiva, va a dar consistencia al muro. El remate del muro es de época renacentista al repetirse la misma disposición de 


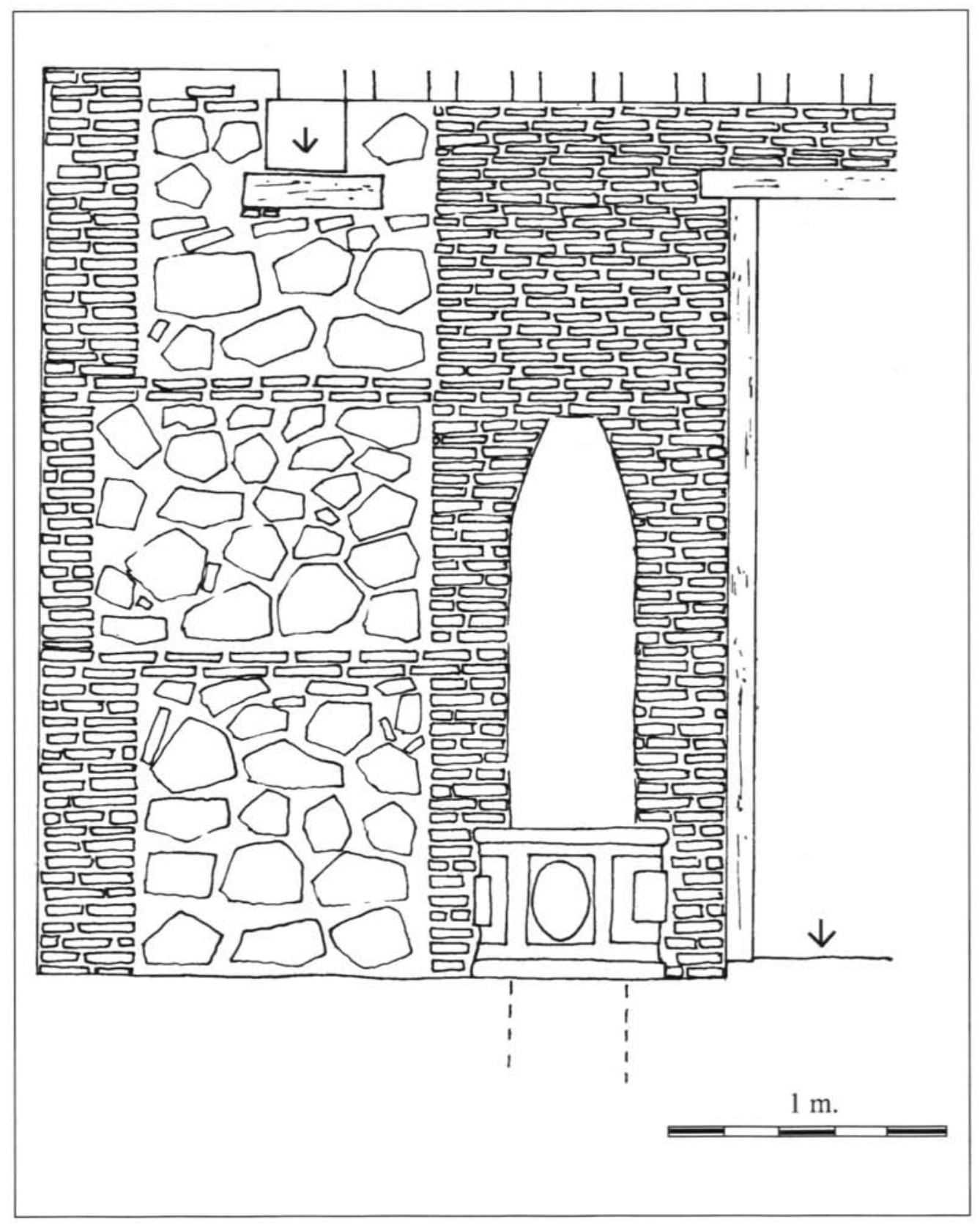

Figura 5. Aparejo mixto, cajones con mampuestos irregulares entre doble verdugada de ladrillos arriba y abajo (Patio, crujía sur, interior del muro frontero). Las flechas marcan el quicio de granito de la puerta, único elemento en piedra de la fachada, y el enjarje de una de las vigas maestras del patio. 


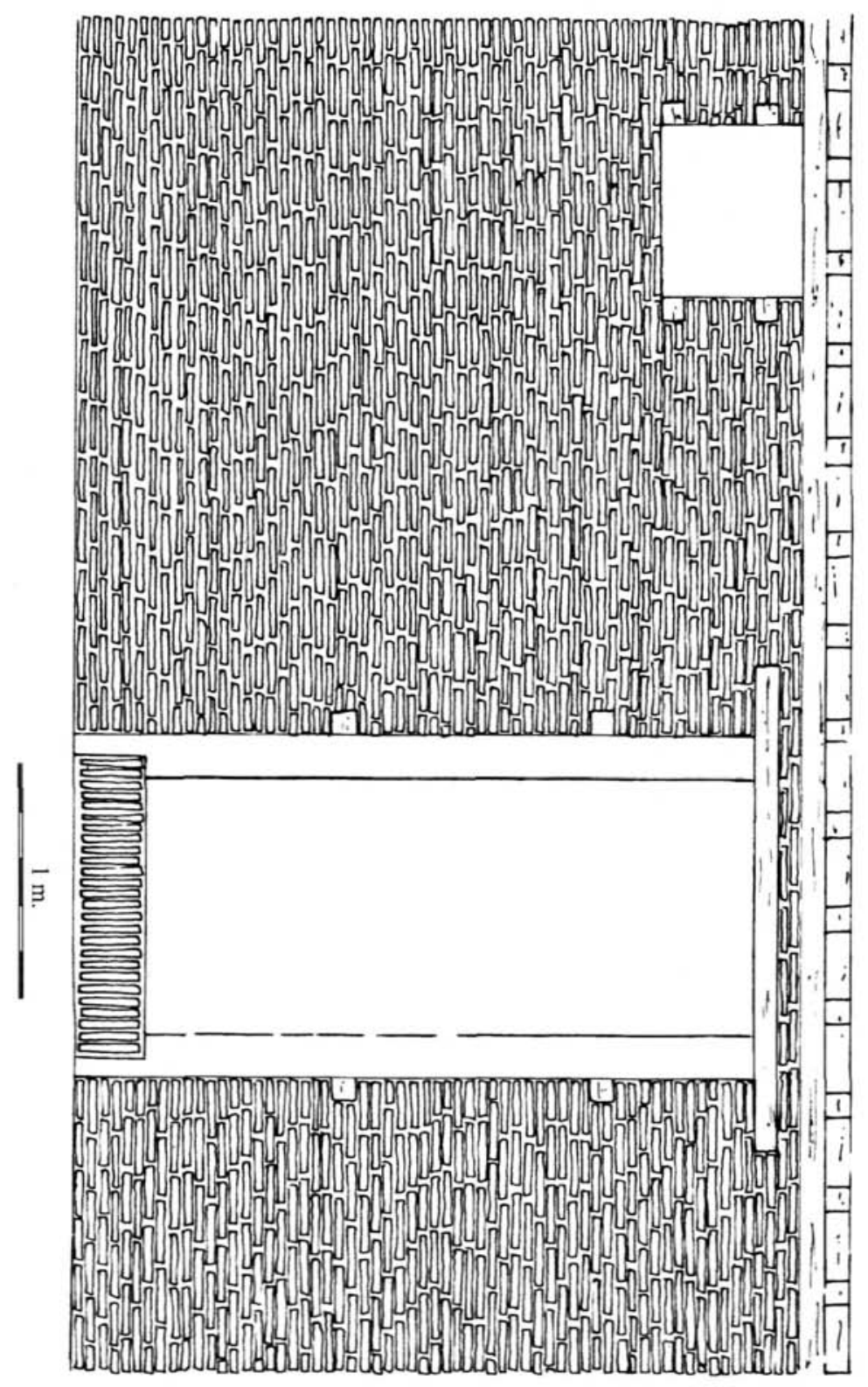

Figura 6. Muro de ladrillo (cara interior del muro de la fachada este, planta baja). En el alzado se refleja el acceso al corral a través de, al menos, un peldaño de escalera y un vano casi a la altura del techo. Esta ubicación puede responder al nivel del suelo del corral con respecto al piso de la habitación. La figura muestra la totalidad del muro interior de la fachada este. 


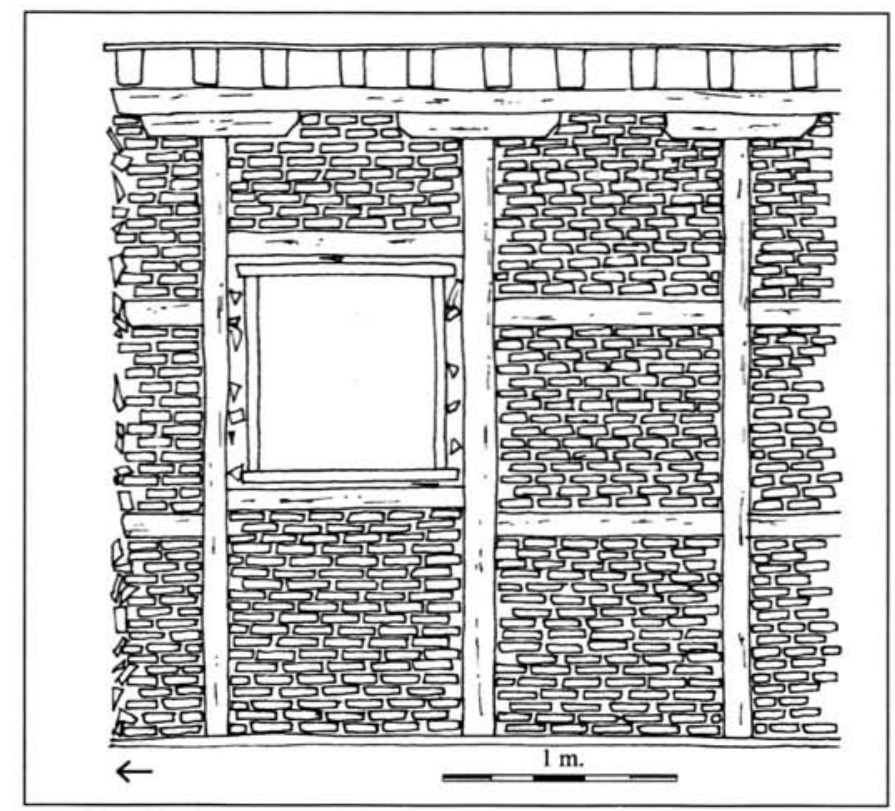

Figura 7. Entramado de vigas de madera con relleno de ladrillo. Planta primera, muro medianero este. Presenta un vano, hoy tapiado, abierto a la zona de corral o huerto. La flecha marca el adosamiento con el muro medianero norte.

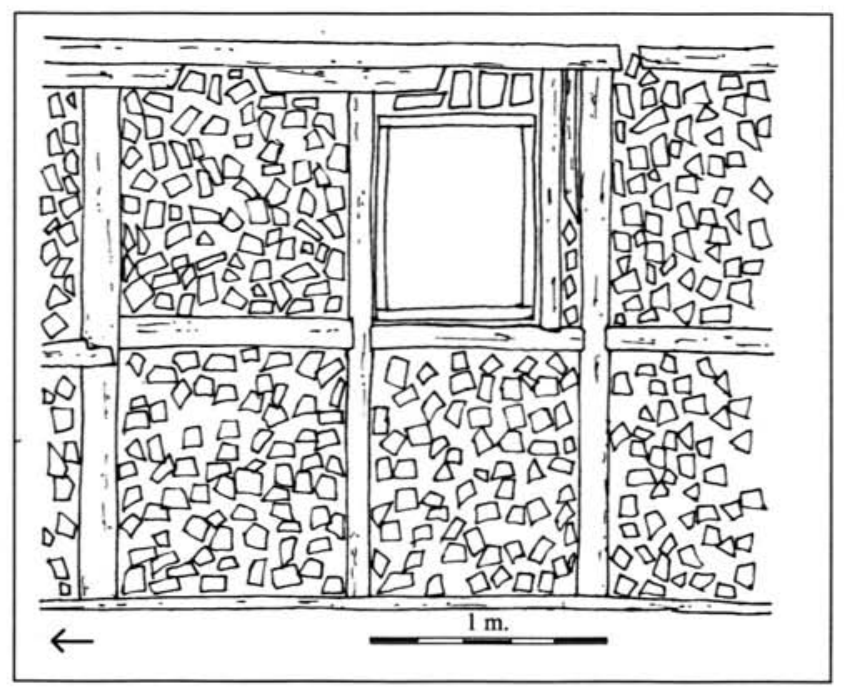

Figura 8. Entramado de vigas de madera con relleno de cascote. Planta segunda, muro medianero este. Presenta un vano, hoy tapiado, ventana a la zona de corral o huerto. La flecha marca el adosamiento con el muro medianero norte. 
ladrillos sobre viga de madera documentada en otras partes de la casa. En este sentido, las diferencias métricas de los ladrillos en los distintos muros es muy significativa: los ladrillos de la obra más antigua en la medianería oeste miden $27 \times 18 \times 3$ centímetros. Los ladrillos de obra renacentista miden $30 \times 20 \times 4$ centímetros en la fachada este planta baja y $26 \times 20 \times 3$ en la fachada este planta primera (la medida no es uniforme para todos los ladrillos, pudiendo existir diferencias de mas menos 1 centímetro).

En el trascurso de las obras de remodelación de la medianería, apareció una pieza de origen romano formando parte del mortero de este muro de tapial (Museo Arqueológico de Santa Cruz de Toledo). Se trata de una base o peana de mármol negro incompleta (Figura 10). Se encuentra dividida en dos cuerpos por un bisel. En uno de los lados del cuerpo inferior se localiza una inscripción latina con el nombre de IVLIVS. La superficie de la pieza conserva las marcas de fijación de la escultura o grupo escultórico del que formó parte. Además, en una de esas marcas se aprecian restos de bronce, lo que sugiere la posibilidad de que la escultura o grupo escultórico fuera de ese metal. La pieza se fecha en los primeros años del s. I. La fractura es posterior y la superficie dañada se encuentra parcialmente pulida.

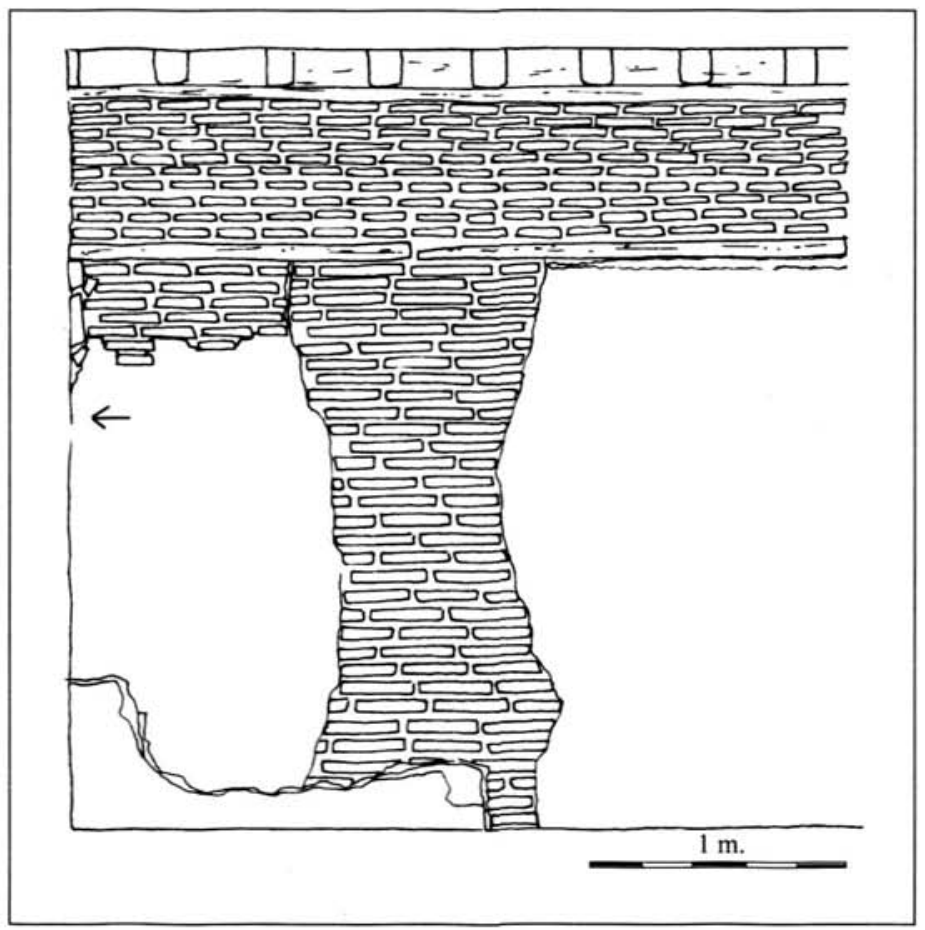

Figura 9. Obra de tapial (renacentista) entre obra de ladrillo (bajomedieval) rematada con viguería de madera y ladrillo (renacentista). Muro medianero oeste. La flecha muestra la línea de adosamiento con el muro de la fachada principal, sur. 


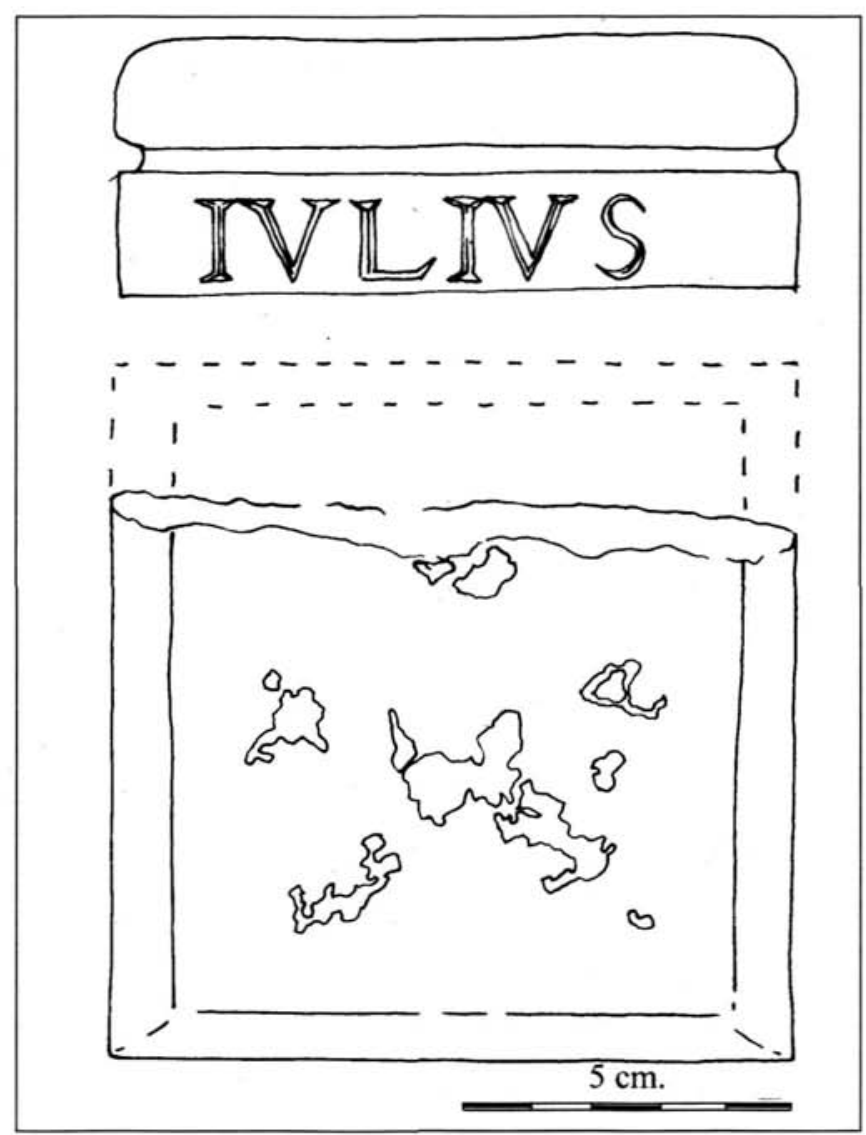

Figura 10. Peana de mármol parte del mortero del tapial del muro medianero oeste, planta primera.

\section{Mamposteria irregular (Figura 11)}

La obra, aunque de pobre factura, es una de las más interesantes del edificio al estar posiblemente relacionada con el orden constructivo de las diferentes crujías de la casa. Mientras que las crujías oeste y norte se encuentran adosadas mediante muros medianeros a las edificaciones colindantes, las crujias sur y este son exentas y forman las fachadas principal y lateral del edificio. La obra de estos muros medianeros norte y oeste es bastante pobre, en algunas ocasiones se reutilizan estructuras murarias de la edificación anterior, como es el caso de la medianería oeste (Figura 9). En otros se emplean obras simples que se sirven de la consistencia de la medianería del edificio adosado para levantar paramentos poco elaborados. Este es el caso del muro localizado en la planta segunda, muro medianero de la crujía norte. Es de suponer que en el orden constructivo de las crujías, la norte a la que pertenece este muro fue la última en construirse. 


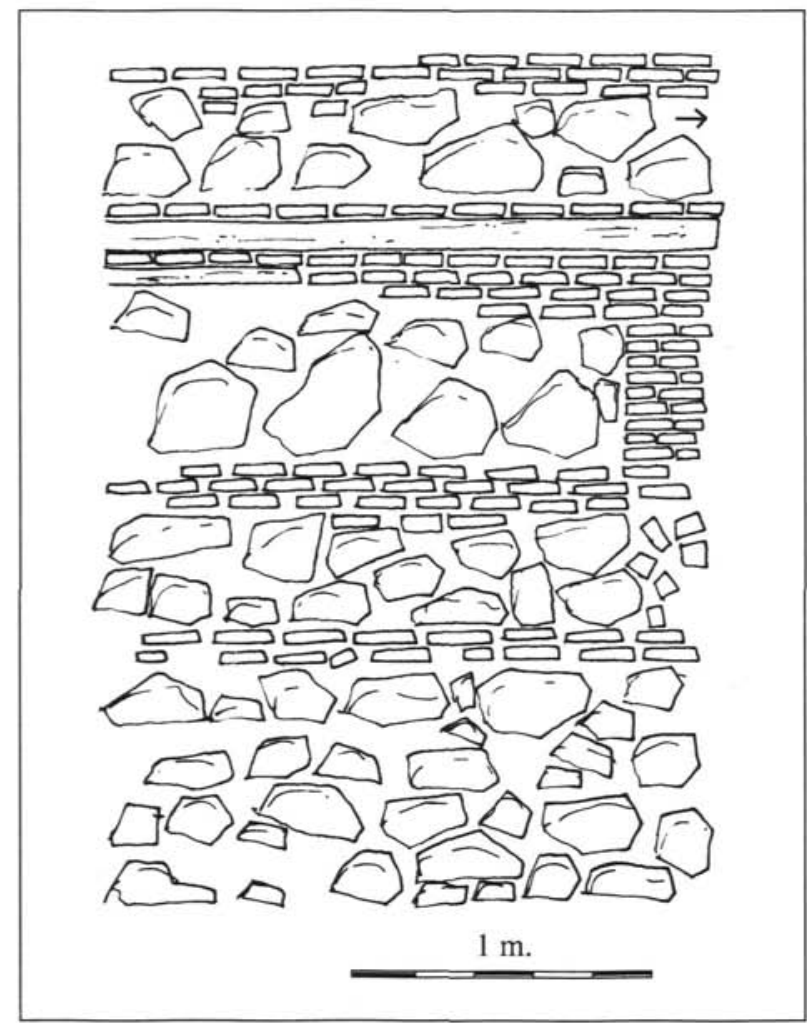

Figura 11. Muro de mampostería irregular. Mixta con ladrillo, cascote y vigas de madera. Muro medianero norte, piso segundo. La flecha muestra la línea de adosamiento con el muro de la fachada este.

\section{ELEMENTOS ORNAMENTALES}

Los elementos ornamentales que hoy se conservan en la casa son tres: brocales, columna y balaustrada. No obstante, en este tipo de edificación la decoración del revoco de su fachada y de las habitaciones interiores representaba un elemento decorativo importante. Además, alguno de los zócalos de las habitaciones pudo estar decorado con azulejería de la época. En estas casas la relación que más se repite es holambrilla de arista con baldosa lisa. Por desgracia, ninguno de estos elementos se ha conservado.

\section{Brocales}

La casa posee dos brocales idénticos labrados en granito con decoración geométrica. Uno pertenece a un aljibe, ahornacinado en el muro frontero sur, del cual no hemos 
podido documentar su alzado por estar lleno de agua. El segundo brocal pertenece a un pozo, se encuentra también ahornacinado. La bajante está comunicada con una de las bóvedas de la casa. La distribución pozo -aljibe o aljibe- aljibe, más común, es frecuente en las casas de Toledo. Esta distribución responde a la necesidad de tener dos fuentes distintas de almacenamiento de agua: una potable y otra no potable.

\section{Columna}

La casa cuenta con una sola columna de granito localizada en la esquina noreste del patio. La columna se compone de fuste y capitel de granito (Figura 12). La obra del capitel es muy interesante al estar diseñada para la posición que ocupa en el patio. Posee una zona no trabajada, no visible, y otra labrada que se ve desde cualquier ángulo del patio. La tipología del capitel se repite en otros edificios contemporáneos de Toledo, por citar un ejemplo, capitales similares los encontramos en el Claustro de Santa Cruz.

El fuste es de granito y conserva una marca en forma de cruz de Israel. Esta marca suele aparecer asociada a contextos de culto o religiosos. El hecho de que la casa no esté catalogada en ese contexto y que se aprecien marcas similares en otras partes del fuste hace pensar en una reutilización del mismo (Figura 13).

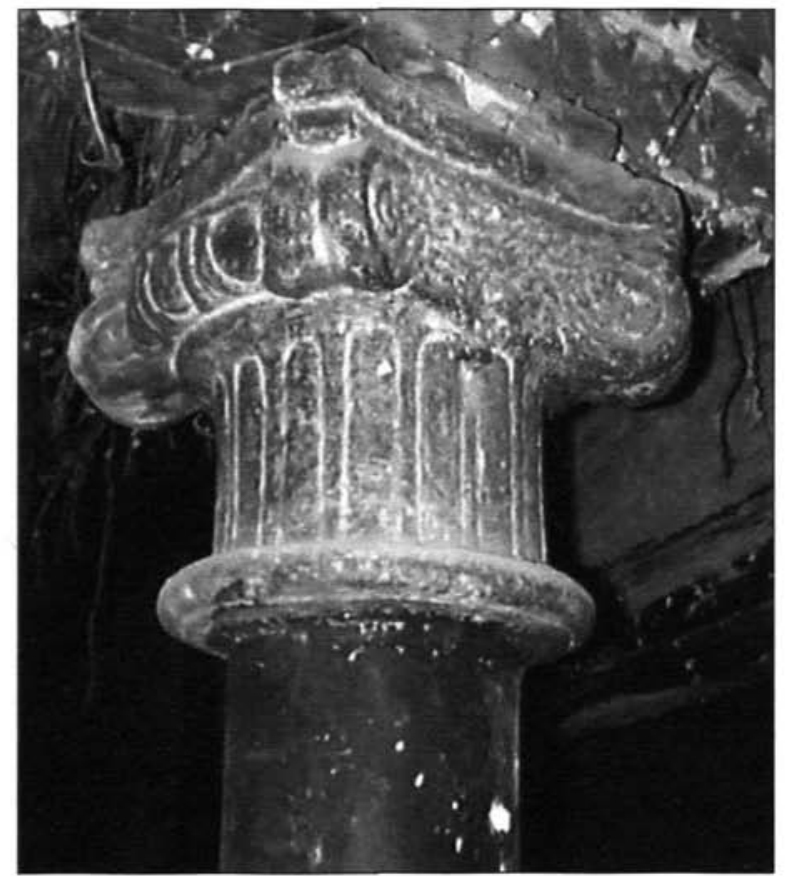

Figura 12. Detalle de la labra del capitel. 


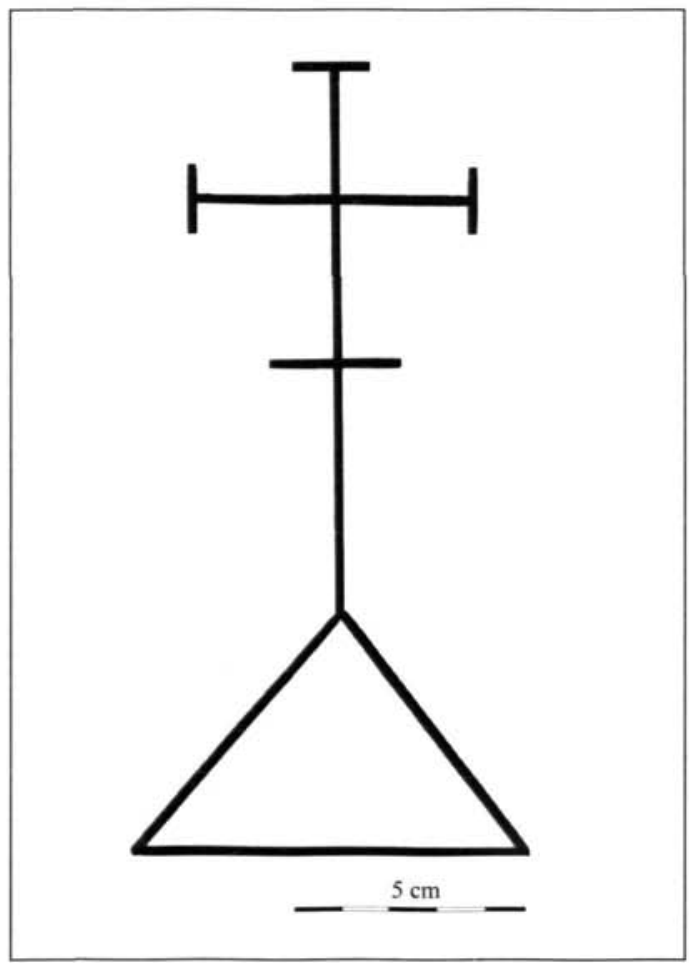

Figura 13. Marca localizada a media altura del fuste de la columna de granito. La marca se localiza en una zona no visible.

\section{Balaustrada}

El material empleado es la madera. Se ha documentado en las dos plantas del edificio sin un diseño uniforme. En la primera planta, la baranda sirve de cierre a las paredes de los cuatro pasillos que dan al patio (Figura 14). Aunque en la actualidad se encuentra tapiada, el estudio de su estructura y diseño ha aportado una serie de datos para comprender este tipo de obras. La balaustrada en esta planta posee una estructura uniforme, con una distancia media de separación entre barrotes de 20 centímetros. Su altura con respecto a la solera del pasillo es de 90 centímetros. En la crujía sur la balaustrada se ve dividida por una viga de madera central.

En la planta segunda se producen los mayores cambios en cuanto a su diseño y su distribución. Aunque la distancia de separación entre barrotes sigue siendo de 20 centímetros, no se ha documentado balaustrada en el pasillo de las crujías este y sur, siendo la oeste la que tiene un acabado similar al de la planta primera. 
La falta de uniformidad en la distribución de la balaustrada puede estar en relación con su orientación visual con respecto a los accesos principales al patio desde la calle y corral respectivamente. Los tramos de barandilla que se ven desde la calle en ambas plantas están completas. Algo similar ocurre con los tramos de barandilla que se aprecian desde la habitación desde la que se accede al corral.

Además de la balaustrada, canecillos de madera completan el embellecimiento de las fachadas del patio como remate a los forjados de las plantas.

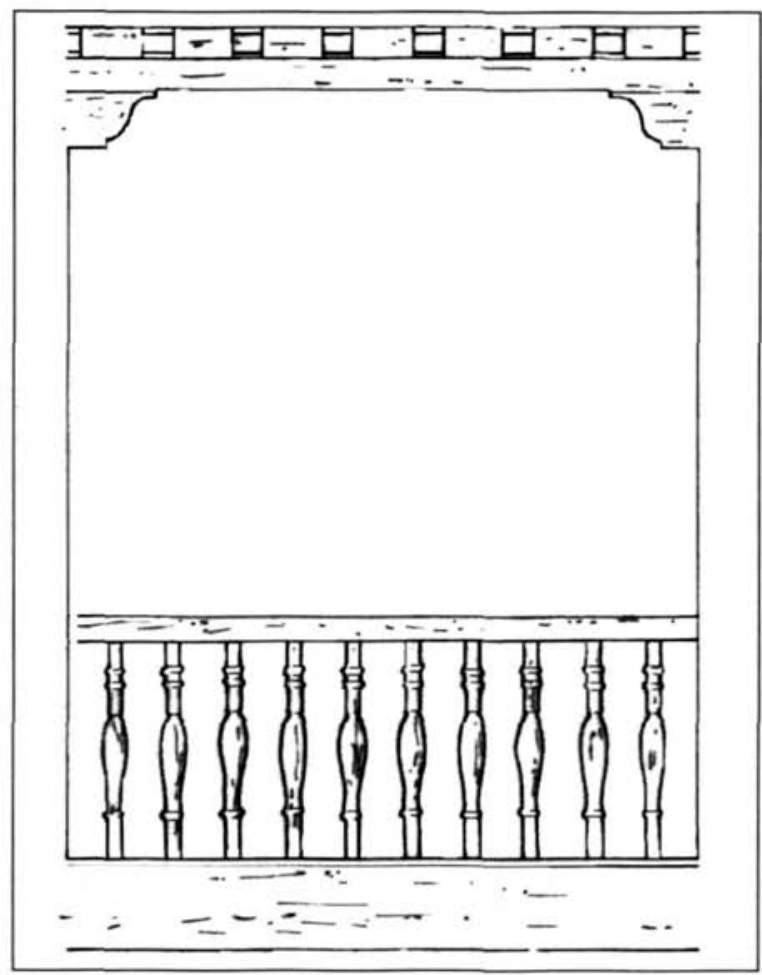

Figura 14- Reconstrucción de la balaustrada corrida de la primera planta. Crujía este.

\section{ARQUEOLOGÍA DE LO COTIDIANO: A MODO DE CONCLUSIÓN}

El estudio arqueológico del inmueble ha permitido conocer alguna de las características de la arquitectura civil popular del período renacentista en Toledo, tipo medio según Marías (1983:177). En algunos casos, se ha podido constatar alguna de las suposiciones ampliamente reconocidas por la literatura tradicional sobre la distribución del espacio y la ordenación interna de estas casas. En otros, se ha prestado especial atención a la 
combinación de elementos funcionales dentro del espacio de habitación. Entre estos elementos destacan la alternancia de pozo-aljibe, documentada en otras casas como aljibe-aljibe, en relación al almacenamiento de agua.

El análisis de la edificación ha permitido contrastar los datos históricos sobre la evolución urbanística del entorno. Se ha demostrado arqueológicamente la información recogida en las fuentes escritas sobre la construcción de un nuevo barrio residencial sobre la antigua zona de contacto con la ciudad judía. Aunque la casa renacentista puede ser considerada de nueva planta, es también interesante documentar el uso de estructuras o trazados constructivos más antiguos como complemento a la nueva edificación, práctica habitual en la ciudad de Toledo. La casa aún conserva los restos de la anterior edificación bajomedieval. Por una parte, los sótanos con su acceso original, hoy tapiado y, por otra, el codo del acceso a dicho sótano en el muro medianero oeste, que también conserva parte de su alzado.

Se ha podido comprobar el orden de la edificación mediante el estudio de las diferentes crujías. La primera en levantarse es la crujía oeste. Esta aprovecha los restos murarios de la edificación anterior y se cimienta sobre una de las bóvedas existentes. La segunda es la crujía este que forma una de las dos fachadas de la casa. Su obra es completamente nueva y no aprovecha ningún elemento arquitectónico anterior (Figura 15). Esta edificación en bloques se termina posiblemente con la construcción de la fachada principal, que sirve de cierre y conexión a las dos crujías ya edificadas y, por último, con la construcción de la crujía norte. Esta última crujía se sirve estructuralmente, por una parte, del resto de crujías ya terminadas y, por otra, de la finca medianera.

En definitiva, sin ser uno de los suntuosos palacios renacentistas a los que la literatura especializada nos tiene acostumbrados, la casa no deja de ser un elemento clave para comprender un tipo de arquitectura poco considerado en la ciudad de Toledo y que, curiosamente, es el más abundante. 


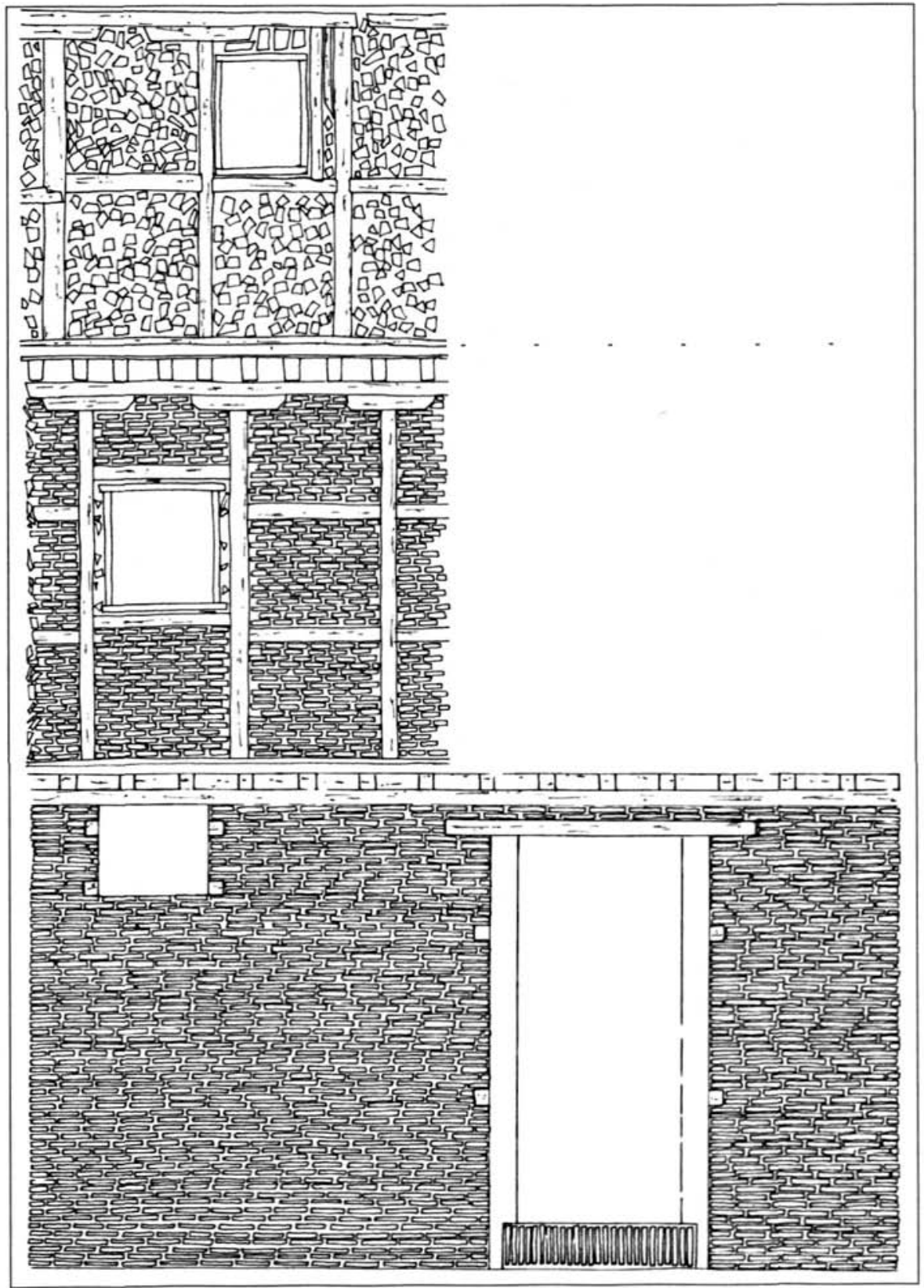

Figura 15. Composición que muestra el alzado interior de la fachada este (Figuras 6, 7 y 8). 


\section{BIBLIOGRAFIA}

BARRIO ALDEA, C. y MAQUEDANO CARRASCO, B. (1996): Calle Alfonso X el Sabio, 6. En Toledo; arqueología en la ciudad, Servicio de Bienes de Interés Cultural de la Consejería de Educación y Cultura de la Junta de Comunidades de Castilla La Mancha: 117-125

BUSQUETS MORENO, C. (1996): Toledo. Plan Especial del Conjunto Histórico. Toledo.

CARROBLES SANTOS, J. (1990) Introducción a la arqueología urbana en la ciudad de Toledo. Actas del I Congreso de Arqueología de la Provincia de Toledo. Diputación Provincial de Toledo.

- (2001) Reseña histórica. Sector 19, Callejón de las Siete Revueltas. Sectores de Rehabilitación integrada del Plan Especial del Conjunto Histórico de Toledo. Estudio Fernández del Amo (Memoria)

CARROBLES SANTOS, J. y RUIZ TABOADA, A. Coor. (2001): Actas del If Congreso de Arqueología de la Provincia de Toledo. Diputación Provincial de Toledo, Volumen II.

CASTAÑOS Y MONTIJANO, M. (1918): Edad de los muros de Toledo. Toletum, 11: 217-218

DÍEZ DEL CORRAL, R. (1987): Arquitectura y mecenazgo: La imagen de Toledo en el Renacimiento. Madrid.

DÍEZ DEL CORRAL, R.; NAVASCUÉS, P. y SUÁREZ QUEVEDO, D. (1992): Arquitecturas de Toledo. Del Renacimiento al Racionalismo. Junta de Comunidades de Castilla La Mancha. Tomo II.

MARÍAS, F. (1983) La arquitectura del Renacimiento en Toledo (1541-1631): Tomo I. Instituto Provincial de Investigaciones y Estudios Toledanos.

- (1985) La arquitectura del Renacimiento en Toledo (1541-1631). Tomo II. Instituto Provincial de Investigaciones y Estudios Toledanos.

- (1986a) La arquitectura del Renacimiento en Toledo (1541-1631). Tomo III. Instituto Provincial de Investigaciones y Estudios Toledanos.

- (1986b) La arquitectura del Renacimiento en Toledo (1541-1631) Tomo IV. Instituto Provincial de Investigaciones y Estudios Toledanos.

PORRES MARTÍN CLETO, J.; DEL CERRO MALAGÓN, R. y ISABEL SÁNCHEZ, J. L. (1992): Panorama de Toledo de Arroyo Palomeque. Diputación Provincial de Toledo.

MIRANDA SÁNCHEZ, A. (1995): Muros de Toledo. Instituto Provincial de Investigaciones y Estudios Toledanos. Colegio de Arquitectos de Castilla La Mancha.

PAZ ESCRIBANO, M y DE JUAN GARCÍA, A. (1996): Museo de Arte Contemporáneo. En Toledo; arqueología en la ciudad. Servicio de Bienes de Interés Cultural de la Consejería de Educación y Cultura de la Junta de Comunidades de Castilla La Mancha: 45-49

ROJAS RODRÍGUEZ MALO, J. M. (1996): Santo Tomé 5. En Toledo; arqueología en la ciudad, Servicio de Bienes de Interés Cultural de la Consejería de Educación y Cultura de la Junta de Comunidades de Castilla La Mancha: 249-260 
ROJAS RODRÍGUEZ MALO, J. M. y VILLA GONZÁLEZ, R. (1999a): Origen y evolución del aparejo toledano entre los siglos X y XVI. II Congreso de Arqueología Peninsular. Zamora, septiembre de 1996.

- (1999b) Las casas islámicas toledanas. En Actas del Congreso Internacional Entre el califato y la taifa: Mil años del Cristo de La Luz. Toledo: 197-243.

RUBIERA MATA, M. (1991): Los primeros moros conversos o el origen de la tolerancia. En Cardaillac (Dir.) Toledo s. XII y XIII; 109-117.

TÉLLEZ, G. (1948-1949): La casa toledana. Revista de la Real Academia de Bellas Artes y Ciencias Históricas de Toledo. Años XXVI-XXVII, número 62-63; 1-63.

VV.AA. (1999): Tratado de Rehabilitación. Universidad Politécnica de Madrid. 